\title{
EMDEN, Christian \\ J. Nietzsche on language, consciousness, and the body. Urbana and Chicago: University of Illinois Press, 2005. 240p. ${ }^{1}$
}

\section{Laura Elizia Haubert}

Graduação em Filosofia (2017). Pontifícia Universidade Católica de São Paulo - PUC-SP. Faculdade de Filosofia, Comunicação, Letras e Artes - Perdizes - 05014901 - São Paulo, SP - Brasil

A obra publicada em 2005 por Christian J. Emden - Professor de História Intelectual Alemã e Pensamento Político na Rice University -, compõe o International Nietzsche Studies com enfoque no desenvolvimento dos conceitos de linguagem, consciência e corpo que se apresentam centrais no pensamento de Nietzsche.

O escopo de Emden nesta obra é duplo, primeiro o autor deseja traçar o desenvolvimento histórico das ideias por trás destes conceitos de Nietzsche, para isto ele expõe o contexto da filosofia alemã neste período, suas influências, discussões e o conhecimento de Nietzsche a respeito destas; segundo ele busca reescrever o desenvolvimento de Nietzsche da década de 1870 a 1880, que culmina no que o autor nomeia de "anthropology of knowledge".

Emden ao elaborar um trabalho mais histórico a respeito da filosofia nietzschiana do período (1870-1880), concentra-se em pontuar o envolvimento do autor alemão com as preocupações científicas e estéticas de sua época, a partir de leituras de autores como Rudolph Hermann Lotze, Hermann von Helmholtz, Emil Du Bois-Reymond, Gustav Teichmüller, Wilhelm Wundt, Friedrich Albert Langue, dentre outros citados por Emden.

O livro parte de uma abordagem que considera os escritos de Nietzsche ambíguos, pois o próprio ambiente intelectual, cultural e político que o filósofo está inserido partilha destas mesmas características. Diante desta ambiguidade, Emden mapeia nos escritos de Nietzsche a linguagem, a consciência e o corpo, reconstruindo as influências por trás destes conceitos.

\footnotetext{
${ }^{1}$ Sem tradução no Brasil.
} 
A obra é dividida em cinco capítulos. O primeiro capítulo intitulado "The irreducibility of language: the history of rhetoric in the age of typewritters" remonta a trajetoria do tema da retórica para Nietzsche salientando, sobretudo, os anos em que foi professor de Filologia na Universidade da Basileia, período em que anunciou nove palestras e cursos sobre o assunto, embora quatro destes não tenham ocorrido.

O enfoque é dado a compreensão de Nietzsche, que arranca em 1870, a partir da relação entre retórica e filosofia influenciado por seus estudos da Antiguidade Clássica, os sofistas, os pré-socráticos e o espaço da retórica na cultura grega. Neste primeiro período Nietzsche define a linguagem como retórica. Emden trabalha a retórica dos antigos e as influências contemporâneas de autores como Gerber exerceram em Nietzsche neste período.

Emden trata também do curioso caso da máquina de escrever que Nietzsche utiliza algumas vezes no ano de 1882, dez anos após seus escritos de retórica. A máquina apresenta uma grande dificuldade para Nietzsche, que acaba a abandonando após utilizar para escrever cartas. A máquina é um curioso sinal das mudanças culturais, e para Nietzsche, de acordo com Emden, representa os efeitos da tecnologia e da reorientação, tanto da غ̇ंı

O segundo capítulo intitula-se "The failures of empiricism: language, science, and the philosophical tradition", no qual Emden inicia com uma exposição do panorama da linguagem, a retórica em descrédito, a ascensão dos estudos e teorias linguísticas comparativas com Franz Bopp e Friedrich Schlegel, bem como a tentativa de reconstruir uma protolinguagem Indo-Europeia, além do levante, cada vez mais comum, das questões que conectassem a linguagem e o conhecimento. Nietzsche tem amplos interessantes tanto pelos trabalhos históricos de retórica, como pelos debates contemporâneos de linguística comparada.

De acordo com Emden, Nietzsche passa por uma mudança de interesse, no início de sua pesquisa ele se foca nas relações entre retórica e filosofia, contudo, o filósofo se desloca para o problema da linguagem e do pensamento em seguida. Nesta instância, Nietzsche destaca as ligações entre cultura e linguagem e os modelos intelectuais resultantes, dito de outro modo, entre o espaço cultural da linguagem, e seu impacto no pensamento.

Emden concentra-se, em seguida, em clarificar a afirmação de Nietzsche de que a linguagem é retórica, e por isto ela não se refere à realidade, nem de modo direto, nem de modo necessário. Emden reconstrói o argumento de Nietzsche destacando a influência de Kant, Schopenhauer e o problema da verdade como correspondência. Uma vez que a linguagem não tem acesso direto à realidade, Emden apresenta qual seria então a função da linguagem neste primeiro momento do pensamento nietzschiano, bem como o seu encontro com o problema do conhecimento, noções de realidade de coisa-em-si e suas influências.

O terceiro capítulo "What is a trope? The discourse of metaphor and the language of the body", preocupa-se em expor as reflexões de Nietzsche em um segundo momento, em que sua filosofia da linguagem, une-se com o problema da consciência e da percepção, além de uma noção particular de corpo. Neste sentindo, explica Emden, a metáfora que Nietzsche identifica como linguagem é fundada não apenas na retórica, mas também na fisiologia.

Emden mapeia a historicidade da metáfora abordada por Nietzsche, e sua importância em relação a linguagem para a compreensão de sua definição, bem como os seus limites cognitivos. A linguagem é uma metáfora que se tornou literal, esqueceu-se do caráter metafórico e artístico que ela implica, e este é um dos principais problemas segundo o filósofo alemão: o esquecimento.

O quarto capítulo "The nervous systems of modern consciousness: metaphor, physiology, and the self", atenta para a extrapolação, ocorrida por meio do termo metáfora, na 
compreensão de Nietzsche, que não se limita apenas ao pensamento tradicional, mas alcança uma dimensão antropológica para o filósofo alemão.

Emden explicita as influências de Nietzsche em leituras de fisiologia e psicologia como Rudolf Virchow, Wilhelm Wundt e Johannes Müller, além de Gustav Gerber e Friedrich Albert Lange, e seu impacto na conceituação de Nietzsche, da linguagem da consciência e do corpo.

O capítulo contempla ainda, uma contextualização da ciência da época de Nietzsche, e os estudos médicos de fisiologia e psicologia, que interessaram a ele, influenciando a elaboração de seu conceito de metáfora como transferência ou transposição. No entanto, não se deve afirmar que Nietzsche reduziu os conceitos mentais a processo físicos, porém, contemplar a ambiguidade que há na elaboração da filosofia de Nietzsche sobre o tema da linguagem, da consciência e do corpo.

O livro encerra-se com o capítulo cinco "Interpretation and life: outlines of na anthropology of knowledge", que se volta aos temas da crítica da metafísica e o problema do conhecimento e da lógica, bem como, a questão da fisiologia da interpretação, e sua relação com a linguagem e a memória.

Emden ainda concentra em retraçar a noção de verdade, moralidade e a "história natural", que retornam para a questão fisiológica e linguística, demonstrando que a relação entre estes conceitos culmina em Nietzsche em um repensar da linguagem, consciência e corpo de modo antropológico, ou seja, humanizando estes temas.

A leitura do livro é indispensável para a compreensão de que em Nietzsche, a linguagem não pode ser abordada sozinha, mas se encontra em uma relação imprescindível com a consciência e o corpo, embasado nos estudos fisiológicos, filosóficos e científicos do século XIX, e não apenas nos estudos clássicos, situando Nietzsche dentro da história da filosofia, bem como em um diálogo com seus contemporâneos.

Correspondência: Laura Elizia Haubert. Pontifícia Universidade Católica de São Paulo - PUC-SP. Faculdade de Filosofia, Comunicação, Letras e Artes. Rua Monte Alegre, 984. Perdizes. São Paulo - SP - Brasil. CEP: 05014-901. E-mail: eliziahaubert@hotmail.com

Apoio financeiro: CNPq

Conflito de interesses: Nenhum

Todos os autores leram e aprovam a versão final submetida à revista Em curso.

Recebido em: 30/Jan/2017 - Aceito em: 05/Set/2017. 